\title{
Optimal Process/Reprocess Production Mix for Multiple Orders in Multiple Periods
}

\author{
Hsiao-Fan Wang* and Hung-Shi Lin \\ Department of Industrial Engineering and Engineering Management, National Tsing Hua University, Hsinchu, Taiwan, Republic of China
}

\begin{abstract}
Production planning, which allows the manufacturer to efficiently manage all production activities, is a major issue in manufacturing/processing industries. This study considers a medium-term production planning problem, in which a producer receives several periodic orders from multiple retailers at the beginning of the planning horizon. Given the limit in production capacity, the producer must reject some orders under the profit maximization principle, while considering multiple and inseparable orders, backlogging policy, and capacity limitation of the plant. Therefore, the producer faces two issues, namely, (a) which orders the producer should accept, and (b) how to allocate the products to the retailers. To solve these problems, we propose a multiple-period production plan in the form of an integer program. Theoretical development with numerical examples is provided. The results have shown that this study can help producers deal with a more realistic environment and derive useful product delivery information.
\end{abstract}

Keywords: Closed-loop supply chain management; Inventory management; Multiple orders; Multiple periods; Integer programming; Complexity analysis; Sufficient condition

\section{Introduction}

Considering environmental issues, researchers have exerted considerable effort in exploring sustainable development, aimed at easing the deterioration of the natural environment. Among these efforts, the concept of remanufacturing is developed to achieve such goal by saving materials. Remanufacturing refers to the process by which a producer can return the quality of used products to at least the same as that of new products, but with less energy and resource consumption [1]. Given its profitability and environmental friendliness, the company and entire society could benefit from remanufacturing in terms of reduced costs, lower prices for the consumers, and minimized demand for materials, and energy [2]. In recent years, numerous studies on production planning problem have been published. Most studies consider the case in which the producer receives one batch of orders for each period at the beginning of the planning horizon [3-6]. This assumption is contrary to actual practice where producers often receive multiple orders from retailers, which place their periodic orders at the beginning. Thus, considering the logistical and management concerns of backlogging and inability to meet retailers' expectations (i.e., the quantity of products specified in every accepted order must be met), respectively, the producer faces two questions:

1. Which orders should the producer accept?

2. How should the producer allocate products to retailers within a multiple-period planning?

This study aims to investigate these issues and provide a more flexible model for analysis.

This study is organized into sections. First, we review the research that focus on the production plan in a closed-loop supply chain system and identify the unsolved issues at the end of the section. Second, we propose a mathematical model in the form of an integer program to deal with the unsolved issues. The properties of the proposed model are also investigated. Third, a numerical example is provided to show how the model works. Finally, we conclude by stating the contributions of this study and identifying future research directions.

\section{Literature Review}

"Remanufacturing" differs from "reconditioning" and "repair" because the goal of remanufacturing is to recover the quality of a used product to that of a new product in such a way that materials and energy are not wasted. Sutherland et al. [7] compared the energy consumption of the manufacturing and remanufacturing of a diesel engine. Their results showed that, when remanufacturing is applied, energy consumption and greenhouse gas emissions can be reduced significantly, especially if core remanufacturability is increased. Richter and Sombrutzki [5] proposed a remanufacturing plan based on the Wagner/Whitin model. They added the reverse flow to the original Wagner/Whitin model and formulated a model of the alternative application of manufacturing and remanufacturing. Their model aimed to minimize the setup costs of manufacturing/remanufacturing and the inventory costs of new/used products. However, their model does not consider the recycle cost, disposal cost, capacity, and amount of products produced at each period. They also assumed that the demand must be satisfied at each period [5]. Golany et al. [1] considered a production and remanufacturing planning (PRP) problem and proposed a model to minimize the total cost. Unlike the model of Richter and Sombrutzki [5], Golany et al. [3] replaced setup costs with manufacturing and remanufacturing costs. They also considered the disposal cost induced from disposing returned products. By reducing the PRP to a $0 / 1$ knapsack problem, they proved that the problem is an NP-hard problem when costs generally have concave forms; they also showed that the problem can be resolved by utilizing a polynomial time algorithm when costs have linear forms. Pan et al. [4] proposed a single-item capacitated dynamic lot-sizing program. They introduced a

*Corresponding author: Hsiao-Fan Wang, Department of Industrial Engineering and Engineering Management, National Tsing Hua University, Hsinchu, Taiwan, Republic of China, Tel: +886-3-571-513; E-mail: hsiaofanwang@gmail.com

Received November 12, 2014; Accepted November 26, 2014; Published December 03, 2014

Citation: Wang HF, Lin HS (2014) Optimal Process/Reprocess Production Mix for Multiple Orders in Multiple Periods. Ind Eng Manage 3: 144. doi: 10.4172/21690316.1000144

Copyright: ( 2014 Wang HF, et al. This is an open-access article distributed under the terms of the Creative Commons Attribution License, which permits unrestricted use, distribution, and reproduction in any medium, provided the original author and source are credited. 
capacity limitation into their model, characterized useful properties for the general concave cost functions, and discussed several simplified but useful specific cases of their problem. Most recently, Wang and Fu [6] proposed a batch production plan, in which the production quantity at each period is presented in batches and permitted a backlogging policy. Therefore, products can be supplied even after the product delivery period. Considering the growing concern for the natural environment, they also addressed the issue of carbon emission. Many issues on multiple-period production planning in a closed-loop supply chain have been studied in recent works. However, some problems still need to be resolved, such as the number of products delivered to the retailers at each period. Most studies assumed only one batch order at each period, which needs to be satisfied. In the real world, a producer does not always serve one retailer, but serves two or more with multiple orders. Retailers inevitably increase transportation and ordering costs if they divide one order into several parts and then allocate these partial orders to different producers; hence, they require full satisfaction when the producer accepts the order.

Under these circumstances, the first issue is which order(s) should be accepted to maximize the profit of the manufacturer. If backlogging is permitted, then the second issue is the allocation of the products to each retailer or, more precisely, each order of a retailer in a multipleperiod planning horizon. In the next section, we shall state the problem formally and propose a mathematical model to deal with these two issues.

\section{Model Formulation}

\section{Problem statement}

Consider a process/reprocess plant that sells only one kind of product and the company receives orders from its customers at the beginning of the planning horizon. Considering the capacity limit, the plant may not satisfy all the orders. By considering the possibility of loss of its retailers, the manager decides that at least a minimum number of orders must be satisfied. The order can be satisfied using the backorder policy, for which a penalty cost, may be included for the

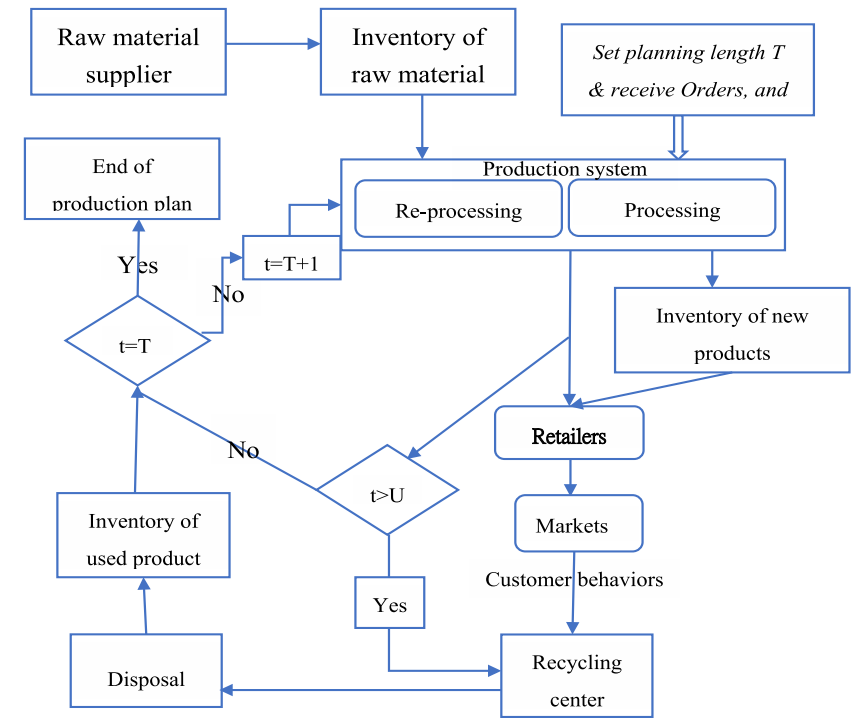

Figure 1: The Structure of Periodic Closed Loop Supply Chain The Structure of Periodic Closed Loop Supply Chain. delay of delivery. The products could be reprocessed after recycling from customers. Although profit varies with different combinations of satisfied orders, the goal of the company is to maximize its net profit. Therefore, the aim of this study is to develop an analytical model to support the target of the manager to achieve the maximum net profit.

Figure 1 shows the structure of this study.

Before formulating the model, we state the assumptions first.

\section{Assumptions}

1. Reprocessed products are regarded as the same as processed products. Therefore, these products are processed along the same production lines and compete for capacities.

2. Once accepted, the order must be satisfied within the planning horizon or within the maximal delay period given by each retailer.

\section{Notation definition}

T Planning horizon

$\boldsymbol{U} \quad$ Product lifespan period.

$\boldsymbol{P} \quad$ Net profit.

$\mathrm{TNO}_{j}$ Total number of orders retailer $\mathrm{j}$ gives to producer, $\mathrm{j}=1,2 \ldots \mathrm{J}$

$\boldsymbol{D}_{j}^{t}$ Quantity of products retailer $\mathrm{j}$ needs in period $\mathrm{t} . \mathrm{t}=1,2 \ldots \mathrm{T}$ and $\mathrm{j}=1,2, \ldots, \mathrm{J}$.

$\gamma$ Collection rate.

$C_{k}$ The capacity of machine $\mathrm{k}, \mathrm{k}=1,2, \ldots, \mathrm{K}$.

$C_{R} M_{k}$ The quantity of resource machine $\mathrm{k}$ used for per unit of processing, $\mathrm{k}=1,2, \ldots, \mathrm{K}$.

$\boldsymbol{C M}_{k}$ The quantity of machine $\mathrm{k}$ used for per unit of reprocessing, $\mathrm{k}=1,2, \ldots, \mathrm{K}$

$C \boldsymbol{L}$ Inventory limit of new product.

CRL Inventory limit of returned product.

MRSO ${ }_{j}$ Minimum ratio of accepted orders to total orders for retailer $j, j=1,2, \ldots J$. $T-1)$

$\boldsymbol{d} \boldsymbol{l}_{j} \quad$ The retailer j's maximum tolerable delay periods $(0 \leq d d j \leq$

$R E V$ Unit revenue of sold product.

PC Unit cost of processing.

RPC Unit cost of reprocessing.

HS Unit holding cost of serviceable product.

HR Unit holding cost of returned product.

DC Unit cost of disposal of returned products.

$S C$ Unit cost of setting-up for processing or reprocessing.

OC Unit cost of ordering raw material.

$B C_{j}$ Unit backlogging cost of retailer $\mathrm{j}, \mathrm{j}=1,2, \ldots, \mathrm{J}$.

RC Unit cost of recycling product.

$x^{t}$ The quantity of products processing in period t. $t=1,2, \ldots, T$. 
$y^{t}$ The quantity of products reprocessing in period t. $t=1,2, \ldots, T$.

$i s^{t}$ Inventory of new product at the end of period t. $\mathrm{t}=1,2, \ldots, \mathrm{T}$.

$i \mathbf{r}^{\mathrm{t}}$ Inventory of raw material at the end of period $\mathrm{t} . \mathrm{t}=1,2, \ldots, \mathrm{T}$.

$i \mathbf{m}^{\mathrm{i}}$ Inventory of used product at the end of period t. $\mathrm{t}=1,2, \ldots, \mathrm{T}$.

$z^{\mathrm{t}}$ The quantity of products disposed of in period t. $\mathrm{t}=1,2, \ldots, \mathrm{T}$.

$\boldsymbol{m}^{\mathrm{t}}$ Setup variable, $0-1$ binary variable, $\mathrm{t}=1,2, \ldots, \mathrm{T}$.

$\boldsymbol{n}^{\mathbf{t}}$ Ordering variable, 0 - 1 binary variable, $\mathrm{t}=1,2, \ldots, \mathrm{T}$.

$\boldsymbol{b}_{j}^{t, t^{\prime}}$ The quantity of products supplied in period t' for retailer j's order of period $t . t=1,2, \ldots, T, t^{\prime}=t, t+1, \ldots, T, j=1,2, \ldots J$.

$\boldsymbol{o}^{\mathbf{t}}$ The quantity of raw materials ordered in period t. $\mathrm{t}=1,2, \ldots, \mathrm{T}$.

$\boldsymbol{r}^{\mathrm{t}}$ The quantity of products recycled in period $\mathrm{t} . \mathrm{t}=\mathrm{U}, \mathrm{U}+1, \ldots, \mathrm{T}$.

$\boldsymbol{s}_{\boldsymbol{j}}^{\boldsymbol{t}}$ Binary variable, $\mathrm{t}=1,2, \ldots \mathrm{T}$ and $\mathrm{j}=1,2, \ldots \mathrm{J}$.

\section{Proposed Production Mix Model (PMM)}

In this part, a production planning model, called production mix model (PMM), is developed wherein the revenue and cost functions are assumed linear.

\section{Maximize}

(PMM)

$$
\begin{aligned}
& P=R E V \sum_{\mathrm{t}=1}^{\mathrm{T}} \sum_{\mathrm{j}=1}^{\mathrm{J}} \mathrm{s}_{\mathrm{j}}^{\mathrm{t}} \times \mathrm{D}_{\mathrm{j}}^{\mathrm{t}}-\sum_{\mathrm{t}=1}^{\mathrm{T}}\left(P C \times x^{t}+R P C \times y^{t}+D C \times z^{t}+\right. \\
& \left.S C \times m^{t}+R C \times r^{t}+H S \times i s^{t}+O C \times n^{t}+H R \times i r^{t}+H M \times i m^{t}\right)- \\
& \sum_{\mathrm{j}=1}^{\mathrm{J}} \sum_{t^{\prime}=2}^{\mathrm{T}} \sum_{t=\max \left(t^{\prime}-d l_{j}, 1\right)}^{t^{\prime}} B C_{j} \times b_{j}^{t, t^{*} *}\left(t^{\prime}-t\right)
\end{aligned}
$$

\section{Constraint}

$$
\begin{aligned}
& i s^{t}=i s^{t-1}+x^{t}+y^{t}-\sum_{j=1}^{J} \sum_{t^{\prime}=\max \left(1, t-d l_{j}\right)}^{t} b_{j}^{t^{\prime}, t}, t=1,2, \ldots T \\
& i m^{t}=i m^{t-1}+o^{t}-x^{t}, t=1,2, \ldots, T . \\
& i r^{t}=i r^{t-1}+r^{t}-z^{t}-y^{t}, t=1,2, \ldots, T \\
& r^{t}=\left\lfloor\gamma \times \sum_{j=1}^{J} \sum_{t^{\prime}=\max \left(1, t-U+1-d l_{j}\right)}^{t-U+1} b_{j}^{t^{\prime}, t-U+1}\right\rfloor, t=U, U+1 \ldots T . \\
& \sum_{t^{\prime}=t}^{\min \left(d l_{j}+t, T\right)} b_{j}^{t, t^{\prime}}=D_{j}^{t} \times s_{j}^{t}, j=1,2, \ldots . J, t=1,2, \ldots, T \\
& C M_{k} x^{t}+C R M_{k} y^{t} \leq C_{k}, t=1,2, . T, k=1,2 . ., K . \\
& i s^{t} \leq C L, t=1,2, \ldots, T . \\
& i r^{t} \leq C R L, t=1,2, \ldots, T . \\
& i m^{t} \leq C M L, t=1,2, \ldots, T . \\
& y^{t} \leq i r^{t-1}, t=1,2, \ldots, T . \\
& \sum_{t=1}^{T} s_{j}^{t} \geq M R S O O_{j} \times T N O_{j}, j=1,2, \ldots, J . \\
& x^{t}+y^{t} \leq L \times m^{t}, t=1,2, \ldots, T .
\end{aligned}
$$

$$
\begin{aligned}
& o^{t} \leq L \times n^{t}, t=1,2, \ldots, T . \\
& \quad s_{j}^{t} \leq D_{j}^{t}, t=1,2, \ldots, T, j=1,2, \ldots, J \\
& \quad x^{t}, y^{t}, o^{t}, i m^{t}, i r^{t}, i s^{t}, z^{t}, r^{t} \text { are non-negativ } \\
& b_{j}^{t, t^{\prime}} \text { is non-negative and integral. } \\
& \quad s_{j}^{t}, m^{t}, n^{t} \text { are binary variables } \in\{0,1\}
\end{aligned}
$$$$
x^{t}, y^{t}, o^{t}, i m^{t}, i r^{t}, i s^{t}, z^{t}, r^{t} \text { are non-negative and integral. }
$$

$L$ is a large number.

The objective function is used to maximize net profit, which is equal to the total revenue minus the costs of processing, reprocessing, recycling, disposal, setup, ordering, inventory, and backlogging. Constraints (2) to (4) refer to the inventory flow conservation of the serviceable products, returned products, and raw materials. Constraint (5) calculates the number of products returned at the end of each period. Constraint (6) ensures that, once the order is accepted, the retailer has to be satisfied before the latest delay period or the end of the planning horizon. Constraint (7) refers to the capacity limitation of the factory, and each production activity consumes these resources. Constraints (8), (9), and (10) refer to the inventory limitations of serviceable products, returned products and raw materials, respectively. Constraint (11) describes the largest number of reprocessed products at each period. Constraint (12) requires that the number of accepted orders for retailer $j$ must exceed the minimum ratio of accepted orders to total orders, which are initially determined by the decision maker. Constraints (13) and (14) define the setup and ordering actions, respectively, such that processing or reprocessing has been completed if $x^{t}+y^{t}>0$. Thus, the setup cost of that period should be counted; otherwise, $m^{t}$ is zero, which denotes no production activity during the period. If $o^{t}>0$, then the producer orders the raw materials at that period. Thus, the ordering cost of that period should be counted; otherwise, $n^{t}$ is zero, which denotes no ordering cost during the period. Finally, constraint (15) ensures that the producer will not accept a zero-quantity order.

Furthermore, constraint (5) is a floor function, and is equivalent to the following two linear forms:

$$
\begin{aligned}
& r^{t} \leq \gamma \times \sum_{j=1}^{J} \sum_{t^{\prime}=\max \left(1, t-U+1-d l_{j}\right)}^{t-U+1} b_{j}^{t^{\prime}, t-U+1}, t=U, U+1, \ldots T \\
& r^{t}+1>\gamma \times \sum_{j=1}^{J} \sum_{t^{\prime}=\max \left(1, t-U+1-d l_{j}\right)}^{t-U+1} b_{j}^{t^{\prime}, t-U+1}, t=U, U+1, \ldots T
\end{aligned}
$$

After transformation, PMM becomes an integer linear programming model, with $T J((T+3) / 2)+10 T$ variables, which are all integers, and $T(11+2 J+\mathrm{K})-2 U+J$ constraints.

\section{Alternative optimal allocation strategy-condition of multiple optimal solutions}

Facilitating flexible management and production requires having an alternative optimal allocation strategy. In this section, we define the alternative allocation strategy first. Then, we show how the alternative optimal allocation strategy could be derived from the original optimal allocation strategy.

Definition 1: Optimal Allocation Strategy

Let $\boldsymbol{B}^{*}=\left[\boldsymbol{B}_{1}^{*}, \ldots, \boldsymbol{B}_{j}^{*}, \ldots, \boldsymbol{B}_{J}^{*}\right]^{T}$ be the optimal allocation strategy for all retailers $j$,

$$
j=1, \ldots, J, \quad \text { where } \quad \boldsymbol{B}_{j}^{*}=\left[b_{j}^{1, *^{*}} b_{j}^{1, *^{*}} \cdots b_{j}^{1, T^{*}} b_{j}^{2,2^{*}} \cdots b_{j}^{T, T^{*}}\right]
$$

with 
Citation: Wang HF, Lin HS (2014) Optimal Process/Reprocess Production Mix for Multiple Orders in Multiple Periods. Ind Eng Manage 3: 144. doi: 10.4172/2169-0316.1000144

Page 4 of 8

$\boldsymbol{V}^{*}=\left[\boldsymbol{x}^{*}, \boldsymbol{y}^{*}, \boldsymbol{z}^{*}, \boldsymbol{r}^{*}, \boldsymbol{i s}^{*}, \boldsymbol{i r}^{*}, \boldsymbol{o}^{*}, \boldsymbol{m}^{*}, \boldsymbol{n}^{*}\right] \quad$ and $\quad \boldsymbol{S}^{*}=\left[\boldsymbol{S}_{1}^{*}, \ldots, \boldsymbol{S}_{j}^{*}, \ldots, \boldsymbol{S}_{J}^{*}\right]^{T} \quad$ with $\boldsymbol{S}_{j}^{*}=\left[s_{j}^{1^{*}}, S_{j}^{2^{*}}, \ldots, S_{j}^{T^{*}}\right]$. Then, $\left(\boldsymbol{V}^{*}, \boldsymbol{S}^{*}, \boldsymbol{B}^{*}\right)$ forms the optimal solution.

\section{Definition 2: Alternative Optimal Allocation Strategy}

Here, $\boldsymbol{B}^{* *}=\left[\boldsymbol{B}_{j}^{* *}\right]$ is called the alternative optimal allocation strategy if $\left(\boldsymbol{V}^{*}, \boldsymbol{S}^{*}, \boldsymbol{B}^{*}\right)$ is an optimal solution, where $\boldsymbol{B}^{* \prime} \neq \boldsymbol{B}^{*}$.

\section{Theorem 1: Sufficient Condition}

Let $\left(\boldsymbol{V}^{*}, \boldsymbol{S}^{*}, \boldsymbol{B}^{*}\right)$ be an optimal solution. Then for any $j$, two periods, $t_{j}^{2}$ and $t_{j}^{1}$, satisfy $t_{j}^{2}>t_{j}^{1} \geq t_{j}^{2}-d l_{j}$. If two periods, $a$ and $c$, in the interval $I=\left[t_{j}^{2}-d l_{j}, t_{j}^{1}\right]$ possess positive $b_{j}^{a, t_{j}^{1}}$ and $b_{j}^{c, t_{j}^{2}}$, respectively, then the alternative optimal allocation strategy exists.

\section{Proof: See Appendix A.}

Five steps are proposed based on the sufficient condition to obtain the alternative optimal allocation strategy, that is, to replace $b_{j}^{a, t_{j}^{\prime}}, b_{j}^{c, t_{j}^{\prime}}$

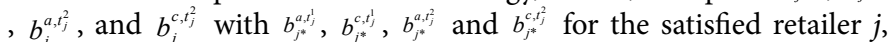
respectively. Table 1 summarizes these steps.

\begin{tabular}{|c|c|}
\hline 1st. & Let $\mathrm{w}=\min \left(b_{j}^{\mathrm{a}, t_{j}^{1}}, b_{j}^{\mathrm{c}, t_{j}^{2}}\right)$ \\
\hline $2^{\text {nd }}$ & $b_{j^{*}}^{\mathrm{a}, t_{j}^{1}}=b_{j}^{\mathrm{a}, t_{j}^{1}}-\mathrm{w}$ \\
\hline $3^{\text {rd }}$ & $b_{j^{*}}^{\mathrm{c}, t_{j}^{1}}=b_{j}^{\left(c, t_{j}^{1}\right)}+w$ \\
\hline $4^{\text {th }}$ & $b_{\left(j^{*}\right)}^{\left(c, t_{j}^{2}\right)}=b_{j}^{\left(c, t_{j}^{2}\right)}-w$ \\
\hline $5^{\text {th }}$ & $b_{\left(j^{*}\right)}^{\left(a, t_{j}^{2}\right)}=b_{j}^{\left(a, t_{j}^{2}\right)}+w$ \\
\hline
\end{tabular}

Table 1: Steps to Obtain Alternative Optimal Allocation Strategy.

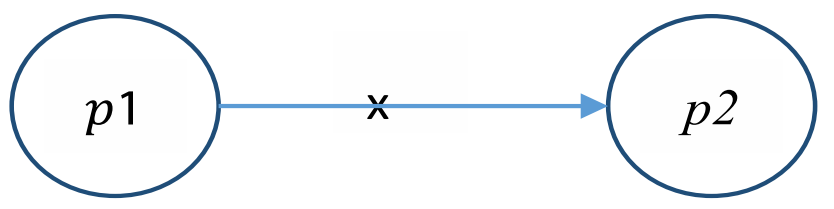

Figure 2: Supply products from period $p 1$ to $p 2$ with $\mathrm{x}$ units, where $p 1>p 2$ ".
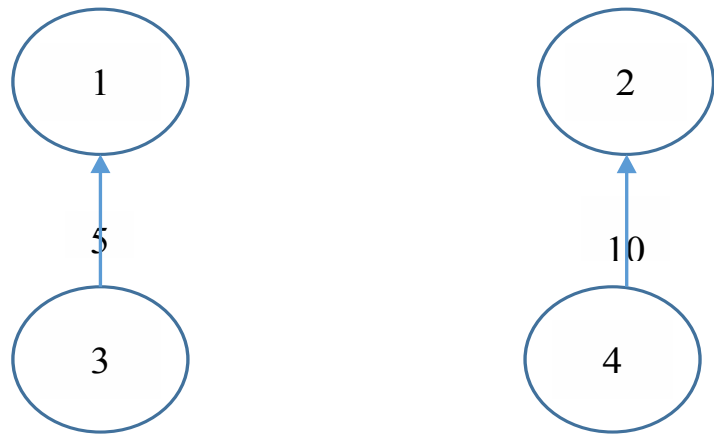

Figure 3: Original Optimal Allocation Strategy for Retailer j.
Figure 2 represents the "supply products from period $\mathrm{p} 1$ to $\mathrm{p} 2$ with $\mathrm{x}$ units, where $\mathrm{p} 1>\mathrm{p} 2$," which explains how Table 1 works.

Next, we suppose that the maximum tolerable delay period of retailer $j, d l_{j}$, is 3 , with the original optimal allocation strategy of retailer $j$ shown in Figure 3. Let us assume $t_{j}^{2}=4, t_{j}^{1}=3, a=1$, and $c=2$, which are in contrast to the conditions of $t_{j}^{2}>t_{j}^{1}$ and $a, c \in\left[t_{j}^{2}-d l_{j}, t_{j}^{1}\right]$ with positive $b_{j}^{a, t_{j}}$ and $b_{j}^{c, t_{j}^{2}}$. Then, using the procedure shown in Table 1, the alternative optimal allocation strategy is obtained and shown in Figure 4.

\section{The reduced PMM}

Reducing the complexity of PMM can decrease the computation time. This reduction is attained by assuming that all retailers allow the largest tolerable delay period equal to $T-1$, that is, $d l_{j}=T-1$ for all $j$. We reduce the PMM to a simpler model that has the same number of constraints, but fewer variables than those of the PMM.

We first define a new variable $b_{j}^{t}$ as the total supply to the order of retailer $j$ at the $t^{\text {th }}$ period, $b_{j}^{t}=\sum_{t^{\prime}=1}^{t} b_{j}^{t^{\prime}, t}$. The modified constraints in the reduced PMM model are summarized below.

Corollary: The reduced PMM has the same optimal solution as the PMM.

Proof: See Appendix B.

\section{The reduced PMM:}

\section{Maximize}

$$
\begin{aligned}
& P=R E V \sum_{\mathrm{t}=1}^{\mathrm{T}} \sum_{\mathrm{j}=1}^{\mathrm{J}} \mathrm{s}_{\mathrm{j}}^{\mathrm{t}} \times \mathrm{D}_{\mathrm{j}}^{\mathrm{t}}-\sum_{\mathrm{t}=1}^{\mathrm{T}}\left(P C \times x^{t}+R P C \times y^{t}+D C \times z^{t}+\right. \\
& \left.S C \times m^{t}+R C \times r^{t}+H S \times i s^{t}+O C \times n^{t}+H R \times i r^{t}+H M \times i m^{t}\right)- \\
& \sum_{\mathrm{j}=1}^{\mathrm{J}} \sum_{t^{\prime}=2}^{\mathrm{T}} \sum_{t=\max \left(t^{\prime}-d l l_{j}, 1\right)}^{t^{\prime}} B C_{j} \times b_{j}^{t, t^{*}}\left(t^{\prime}-t\right)
\end{aligned}
$$

\section{Subject to}

$$
\begin{aligned}
& i s^{t}=i s^{t-1}+x^{t}+y^{t}-\sum_{j}^{J} b_{j}^{t}, t=1,2, \ldots, T \\
& i m^{t}=i m^{t-1}+o^{t}-x^{t}, t=U, U+1 \ldots, T . \\
& i r^{t}=i r^{t-1}+r^{t}-z^{t}-y^{t}, t=U, U+1, \ldots, T . \\
& r^{t} \leq \gamma \times \sum_{j=1}^{J} b_{j}^{t-U+1}, t=U, U+1, \ldots, T . \\
& r^{t}+1>\gamma \times \sum_{j=1}^{J} b_{j}^{t-U+1}, t=U, U+1, \ldots, T . \\
& \sum_{t^{\prime}=1}^{\mathrm{t}} b_{j}^{t^{\prime}}-D_{j}^{t^{\prime}} \times s_{j}^{t^{\prime}} \leq 0, \mathrm{t}=1,2, \ldots, T-1, j=1,2, . ., J . \\
& \sum_{t=1}^{T} b_{j}^{t}=\sum_{t=1}^{T} D_{j}^{t} \times s_{j}^{t}, \text { for } j=1,2, \ldots, J . \\
& C M_{k} x^{t}+C R M_{k} y^{t} \leq C_{k}, t=1,2, \ldots, T, k=1,2, \ldots, K \\
& i s^{t} \leq C L, t=1,2, \ldots, T . \\
& i r^{t} \leq C R L, t=1,2, \ldots, T . \\
& i m^{t} \leq C M L, t=1,2, \ldots, T . \\
& y^{t} \leq i r^{t-1}, t=1,2, \ldots, T . \\
& \sum_{t=1}^{T} s_{j}^{t} \geq M R S O O_{j} \times T N O O_{j}, j=1,2, \ldots, J .
\end{aligned}
$$


Citation: Wang HF, Lin HS (2014) Optimal Process/Reprocess Production Mix for Multiple Orders in Multiple Periods. Ind Eng Manage 3: 144. doi: 10.4172/2169-0316.1000144

Page 5 of 8

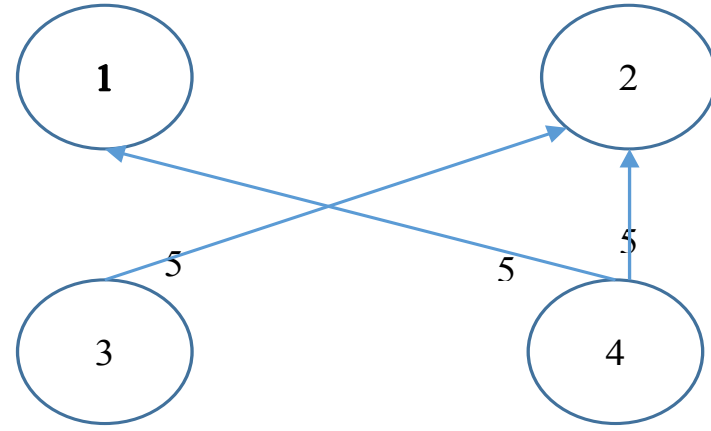

Figure 4: Alternative Optimal Allocation Strategy for Retailer j.

\begin{tabular}{|c|c|c|c|}
\hline & PMM & The Reduced PMM & Difference \\
\hline $\begin{array}{c}\text { Number of } \\
\text { variables }\end{array}$ & $T J((T+3) / 2)+10 T=O\left(T^{2} J\right)$ & $2 T J+10 T=O(T J)$ & $T J=O(T)$ \\
\hline $\begin{array}{c}\text { Number of } \\
\text { constraints }\end{array}$ & $T(11+2 J+K)-2 U+J=O(T(2 J+K))$ & $T(11+2 J+K)-2 U+J=O(T(2 J+K))$ & Same \\
\hline
\end{tabular}

Table 2: Complexity Comparison of PMM and the Reduced PMM.

\begin{tabular}{|c|c|c|c|}
\hline Parameters & value & Parameters & Unit \\
\hline$T$ & 13 periods & $B C$ & {$[4,5,6,5]$ dollars/per product } \\
\hline$J$ & 4 retailers & $R C$ & 2 dollars/per product \\
\hline$K$ & 4 machines & $O C$ & 20 dollars /per product \\
\hline$U$ & 3 periods & $R E V$ & 15 dollars /per product \\
\hline$T N O_{j}$ & {$[13,13,13,13]$ orders } & $P C$ & 10 dollars /per product \\
\hline$Y$ & 0.7 & $R P C$ & 7 dollars /per product \\
\hline$C L$ & 500 new products & $H S$ & 7 dollars /per product \\
\hline$C R L$ & 150 returned products & $H R$ & 5 dollars /per product \\
\hline$M R S O_{j}, j=1, \ldots, 4$ & {$[0.70 .80 .50 .4]$} & $H M$ & 3 dollars /per product \\
\hline$C M L$ & 150 raw materials & $D C$ & 2 dollars /per product \\
\hline$d l_{j}, j=1, \ldots, 4$ & {$[1210]$ periods } & $S C$ & 30 dollars/per period \\
\hline
\end{tabular}

Table 3: Input Parameters.

$$
\begin{aligned}
& x^{t}+y^{t} \leq L \times m^{t}, t=1,2, \ldots, T . \\
& o^{t} \leq L \times n^{t}, t=1,2, \ldots, T . \\
& s_{j}^{t} \leq D_{j}^{t}, t=1,2, \ldots, T, \quad j=1,2, \ldots ., J
\end{aligned}
$$

The remaining constraints are the same as those in the PMM. After we replace the objective function (1) by (16); constraint (2) by (17); constraints (5-1) and (5-2) by (18-1) and (18-2), respectively; and constraint (6) by (19) and (20), we reduce the number of variables by $((T-1) T J / 2)$, whereas the number of constraints remains the same. The complexity comparison between the PMM and the reduced PMM is shown in Table 2 .

Although the reduced PMM minimizes the computation complexity, in reality, all retailers rarely allow delays along the entire planning horizon. Therefore, the reduced PMM is only for theoretical application and not for practical application.

\section{Numerical Example and Analysis}

This section provides numerical examples and the analyses. We first show how the PMM works using an example. After analyzing the parameters, this study provides managerial insights that support the decision-making process. Finally, we provide another example to show the difference of the allocation strategy tableaus between the PMM and the reduced PMM.

\section{Numerical example for the PMM}

In this section, an example is provided to show how our model works with input data indicated in Tables 3-5.

Using the optimization software package, ILOG CPLEX v12.5, an optimal value of 4689 is obtained. The optimal solution is shown in Tables 6-10 (shaded blocks in Table 6 represent the accepted orders, and 0 s in Tables 8-10 represent zero vectors).

\section{Analysis of MRSO for managerial insight}

Intuitively, if the number of accepted orders increases, the profit should also increase. However, the producer can accept more orders because of the backlogging policy. If the penalty of backlogging for an order exceeds the revenue gained by the order, then the profit is expected to decrease. In the PMM, the factor that affects the accepted orders is $\mathrm{MRSO}_{j}$, which is given by the decision maker. Given that a larger $M R S O$ may decrease the profit, the goal of this section is to analyze how the

\begin{tabular}{|c|c|c|c|c|}
\hline $\begin{array}{c}\text { Retailers } \\
\text { Orders }\end{array}$ & R1 & R2 & R3 & R4 \\
\hline $1^{\text {st }}$ & 85 & 95 & 78 & 88 \\
\hline $2^{\text {nd }}$ & 96 & 110 & 90 & 115 \\
\hline $3^{\text {rd }}$ & 150 & 160 & 170 & 152 \\
\hline $4^{\text {th }}$ & 160 & 180 & 170 & 200 \\
\hline $5^{\text {th }}$ & 110 & 60 & 30 & 250 \\
\hline $6^{\text {th }}$ & 60 & 70 & 20 & 300 \\
\hline $7^{\text {th }}$ & 2 & 1 & 2 & 4 \\
\hline $8^{\text {th }}$ & 85 & 95 & 78 & 88 \\
\hline $9^{\text {th }}$ & 96 & 110 & 90 & 115 \\
\hline $10^{\text {th }}$ & 150 & 160 & 170 & 152 \\
\hline $11^{\text {th }}$ & 160 & 180 & 170 & 200 \\
\hline $12^{\text {th }}$ & 110 & 60 & 30 & 250 \\
\hline $13^{\text {th }}$ & 60 & 70 & 20 & 300 \\
\hline
\end{tabular}

Table 4: Periodic Orders.

\begin{tabular}{|c|c|c|c|c|}
\hline $\begin{array}{ll}\text { Orders } & \text { Retailer } \\
\text { Period } & \\
\end{array}$ & R1 & R2 & R3 & R4 \\
\hline $1^{\text {st }}$ & 85 & 95 & 78 & 88 \\
\hline $2^{\text {nd }}$ & 96 & 110 & 90 & 115 \\
\hline $3^{\text {rd }}$ & 150 & 160 & 170 & 152 \\
\hline $4^{\text {th }}$ & 160 & 180 & 170 & 200 \\
\hline $5^{\text {th }}$ & 110 & 60 & 30 & 250 \\
\hline $6^{\text {th }}$ & 60 & 70 & 20 & 300 \\
\hline $7^{\text {th }}$ & 2 & 1 & 2 & 4 \\
\hline $8^{\text {th }}$ & 85 & 95 & 78 & 88 \\
\hline $9^{\text {th }}$ & 96 & 110 & 90 & 115 \\
\hline $10^{\text {th }}$ & 150 & 160 & 170 & 152 \\
\hline $11^{\text {th }}$ & 160 & 180 & 170 & 200 \\
\hline $12^{\text {th }}$ & 110 & 60 & 30 & 250 \\
\hline $13^{\text {th }}$ & 60 & 70 & 20 & 300 \\
\hline $\begin{array}{l}\text { Ratio of accepted orders to } \\
\qquad \mathrm{TNO}_{j}\end{array}$ & $77.0 \%$ & $85.0 \%$ & $61.5 \%$ & $46.2 \%$ \\
\hline
\end{tabular}

\begin{tabular}{|c|c|c|c|c|}
\hline machine $\mathrm{k}=1 \ldots 4$ & 1 & 2 & 3 & 4 \\
\hline Capacity of machine $\mathrm{k}(\mathrm{hr})$ & 800 & 1000 & 1400 & 500 \\
\hline Unit consumption of processing of machine k(hr) & 3 & 5 & 7 & 2 \\
\hline Unit consumption of reprocessing of machine k(hr) & 1 & 2 & 4 & 1 \\
\hline
\end{tabular}

Table 5: Resources and Consumption of Process and Reprocess.

Table 6: Optimal Combination of Accepted Orders 4. 
Citation: Wang HF, Lin HS (2014) Optimal Process/Reprocess Production Mix for Multiple Orders in Multiple Periods. Ind Eng Manage 3: 144. doi: 10.4172/2169-0316.1000144

Page 6 of 8

\begin{tabular}{|c|c|c|c|c|c|c|c|c|c|c|c|c|c|}
\hline Period $t$ & $1^{\text {st }}$ & $2^{\text {nd }}$ & $3^{\text {rd }}$ & $4^{\text {th }}$ & $5^{\text {th }}$ & $6^{\text {th }}$ & $7^{\text {th }}$ & $8^{\text {th }}$ & $9^{\text {th }}$ & $10^{\text {th }}$ & $11^{\text {th }}$ & $12^{\text {th }}$ & $13^{\text {th }}$ \\
\hline Process, $x^{t}$ & 189 & 200 & 200 & 127 & 105 & 120 & 84 & 117 & 114 & 91 & 106 & 114 & 120 \\
\hline Reprocessyt & 0 & 0 & 0 & 127 & 143 & 140 & 150 & 145 & 150 & 110 & 150 & 150 & 140 \\
\hline Disposed, $z^{t}$ & 0 & 0 & 1 & 1 & 0 & 27 & 0 & 59 & 1 & 85 & 34 & 0 & 125 \\
\hline Recycled, $r^{t}$ & 0 & 0 & 128 & 144 & 140 & 177 & 145 & 209 & 111 & 235 & 184 & 140 & 125 \\
\hline Inventory, is ${ }^{t}$ & 6 & 0 & 0 & 0 & 40 & 0 & 75 & 0 & 0 & 0 & 76 & 0 & 0 \\
\hline Inventory, irt & 0 & 0 & 127 & 143 & 140 & 150 & 145 & 150 & 110 & 150 & 150 & 140 & 0 \\
\hline Inventory, im ${ }^{t}$ & 0 & 0 & 0 & 0 & 0 & 0 & 0 & 0 & 0 & 0 & 0 & 0 & 0 \\
\hline Raw material, $o^{t}$ & 189 & 200 & 200 & 127 & 105 & 120 & 84 & 117 & 114 & 91 & 106 & 114 & 120 \\
\hline Setup $m^{t}$ & 1 & 1 & 1 & 1 & 1 & 1 & 1 & 1 & 1 & 1 & 1 & 1 & 1 \\
\hline Ordering, $n^{t}$ & 1 & 1 & 1 & 1 & 1 & 1 & 1 & 1 & 1 & 1 & 1 & 1 & 1 \\
\hline
\end{tabular}

Table 7: Optimal Production Activities.

\begin{tabular}{|c|c|c|c|c|}
\hline Order Supply & $1^{\text {st }}$ & $2^{\text {nd }}$ & $3^{\text {rd }}$ & $4^{\text {th }}$ \\
\hline $1^{\text {st }}$ & $(0,95,0,88)$ & 0 & 0 & 0 \\
\hline $2^{\text {nd }}$ & & $(96,110,0,0)$ & 0 & 0 \\
\hline $3^{\text {rd }}$ & & & $(48,0,0,152)$ & $(102,0,0,0)$ \\
\hline $4^{\text {th }}$ & & & & $(152,0,0,0)$ \\
\hline
\end{tabular}

Table 8: Optimal Periodic Allocation for Retailers (R1, R2, R3, R4) from Periods 1,2,3,4 with Allowed $(1,2,1,0)$ Respective Delay by PMM.

\begin{tabular}{|c|c|c|c|c|}
\hline \multicolumn{1}{|c|}{ Supply } & $5^{\text {th }}$ & $6^{\text {th }}$ & $7^{\text {th }}$ & $8^{\text {th }}$ \\
\hline $1^{\text {st }}$ & $\mathbf{0}$ & $\mathbf{0}$ & $\mathbf{0}$ & $\mathbf{0}$ \\
\hline $2^{\text {nd }}$ & $\mathbf{0}$ & $\mathbf{0}$ & $\mathbf{0}$ & $\mathbf{0}$ \\
\hline $3^{\text {rd }}$ & $\mathbf{0}$ & $\mathbf{0}$ & $\mathbf{0}$ & $\mathbf{0}$ \\
\hline $4^{\text {th }}$ & $(8,0,0,0)$ & $\mathbf{0}$ & $\mathbf{0}$ & $\mathbf{0}$ \\
\hline $5^{\text {th }}$ & $(110,60,30,0)$ & $\mathbf{0}$ & $\mathbf{0}$ & $\mathbf{0}$ \\
\hline $6^{\text {th }}$ & & $(0,0,0,300)$ & $(60,70,20,0)$ & $\mathbf{0}$ \\
\hline $7^{\text {th }}$ & & & $(2,1,2,4)$ & $\mathbf{0}$ \\
\hline $8^{\text {th }}$ & & & & $(76,95,78,88)$ \\
\hline
\end{tabular}

Table 9: Optimal Periodic Allocation for Retailers (R1, R2, R3, R4) from Periods $5,6,7,8$ with Allowed $(1,2,1,0)$ Respective Delay by PMM.

\begin{tabular}{|c|c|c|c|c|c|}
\hline $\begin{array}{c}\text { Supply } \\
\text { Order }\end{array}$ & $9^{\text {th }}$ & $10^{\text {th }}$ & $11^{\text {th }}$ & $12^{\text {th }}$ & $13^{\text {th }}$ \\
\hline $1^{\text {st }}$ & $\mathbf{0}$ & $\mathbf{0}$ & $\mathbf{0}$ & $\mathbf{0}$ & $\mathbf{0}$ \\
\hline $2^{\text {nd }}$ & $\mathbf{0}$ & $\mathbf{0}$ & $\mathbf{0}$ & $\mathbf{0}$ & $\mathbf{0}$ \\
\hline $3^{\text {rd }}$ & $\mathbf{0}$ & $\mathbf{0}$ & $\mathbf{0}$ & $\mathbf{0}$ & $\mathbf{0}$ \\
\hline $4^{\text {th }}$ & $\mathbf{0}$ & $\mathbf{0}$ & $\mathbf{0}$ & $\mathbf{0}$ & $\mathbf{0}$ \\
\hline $5^{\text {th }}$ & $\mathbf{0}$ & $\mathbf{0}$ & $\mathbf{0}$ & $\mathbf{0}$ & $\mathbf{0}$ \\
\hline $6^{\text {th }}$ & $\mathbf{0}$ & $\mathbf{0}$ & $\mathbf{0}$ & $\mathbf{0}$ & $\mathbf{0}$ \\
\hline $7^{\text {th }}$ & $\mathbf{0}$ & $\mathbf{0}$ & $\mathbf{0}$ & $\mathbf{0}$ & $\mathbf{0}$ \\
\hline $8^{\text {th }}$ & $(9,0,0,0)$ & $\mathbf{0}$ & $\mathbf{0}$ & $\mathbf{0}$ & $\mathbf{0}$ \\
\hline $9^{\text {th }}$ & $(55,110,90,0)$ & $(41,0,0,0)$ & $\mathbf{0}$ & $\mathbf{0}$ & $\mathbf{0}$ \\
\hline $10^{\text {th }}$ & & $(0,160,0,0)$ & $\mathbf{0}$ & $\mathbf{0}$ & $\mathbf{0}$ \\
\hline $11^{\text {th }}$ & & & $(0,180,0,0)$ & $\mathbf{0}$ & $\mathbf{0}$ \\
\hline $12^{\text {th }}$ & & & & $(0,60,30,250)$ & $(110,0,0,0)$ \\
\hline $13^{\text {th }}$ & & & & & $(60,70,20,0)$ \\
\hline
\end{tabular}

Table 10: Optimal Periodic Allocation for Retailers (R1, R2, R3, R4) from Periods $9,10,11,12,13$ with Allowed $(1,2,1,0)$ Respective Delay by PMM.

optimal value varies with different values of $\mathrm{MRSO}_{j}$ and, from it, derive managerial insights to support decision making.

To analyze how $M R S O_{j}$ affects the objective value, let $M R S O=\left[M R S O_{1}, M R S O_{2}, \ldots, M R S O_{j}\right]$. Then, two types of variables, $M_{R S O}^{*}$ and $M R S O_{j}^{* *}$ are defined as follows:

$1 . M R S O^{*}$ : the value of the optimal returned profit is the largest, that is, when we set $M R S O_{j} \leq M R S O_{j}^{*}$ for all $\mathrm{j}$, the maximum optimal value is obtained; and
2. $\mathrm{MRSO}^{* *}$ : the largest value wherein the producer can maintain its service level, that is, if $M R S O_{j}>M R S O_{j}^{* *}$ for all $\mathrm{j}$, then the model would be infeasible.

If $M R S O_{j} \geq M R S O_{j}^{*}$ for all $j$, then a trade-off between the profit and the service level is observed, such that the higher the value of $M R S O_{j}^{*}$, the lower the optimal value in the PMM. Although maintaining the service level of a company is important, the service level for each customer is the main issue that the producer should focus on.

Given that the values of $M R S O^{*}$ and $M R S O^{* *}$ may not be unique, in the following, we propose a rule of thumb for determining the MRSO and $M R S O^{* *}$.

To determine, $M R S O^{*}$ we replace constraint (13) with the following:

$\sum_{t=1}^{T} s_{j}^{t}=\left[\operatorname{MRSO}_{j} \times T_{N} \boldsymbol{O}_{j}\right], \quad j=1,2, \ldots, J$.

Each $M R S O$, is regarded as a variable. In the example, the values of $M R S O^{*}$ are $0.2308,0.3846,0.3846$, and 0.5385 . By contrast, we calculate $M R S O^{* *}$ by determining the maximum number of orders that the producer could accept. Then, instead of using constraint (29) to replace constraint (13), we remove constraint (13) and replace the original optimal function with the following:

$$
\max \sum_{j=1}^{J} \sum_{t=1}^{T} s_{j}^{t} \text {. }
$$

For this example, the optimal $\sum_{j=1}^{J} \sum_{t=1}^{T} s_{j}^{t} \quad$ is 38 , and the optimal objective value is $-11,062$. To calculate the value of $M R S O^{* *}$ , we divide the number of accepted orders given by retailer $j$ by the total number of orders given by retailer $j$. From this, we obtain MRSO $^{* *}=[1,0.85,0.69,0.38]$.

Following the previously presented analysis, a procedure to determine MRSO is proposed, which is described below.

1. Set $M R S O=M R S O^{*}$ and solve the model to determine the optimal objective value, optimal solution, and the number of accepted orders for each retailer $q_{j}$.

2. Let $\Delta_{j}$ be the number of extra orders the decision maker wants to deliver to retailer $j$, where $\Delta_{j} \in\left[0, M R S O_{j}^{* *} \times \boldsymbol{T} N \boldsymbol{O}_{j}-q_{j}\right]$. Replace constraint (13) with:

$$
\sum_{t=1}^{T} s_{j}^{t}=\boldsymbol{q}_{j}+\ddot{\mathbf{A}}_{j}, \quad j=\mathbf{1}, \mathbf{2}, \ldots, \boldsymbol{J} .
$$

Reoptimize the model to obtain a satisfactory optimal solution.

\section{Numerical example for the reduced PMM}

To explain the reduced PMM, we consider an example where $d l_{j}$ is equal to $[12,12,12,12]$, and the remaining input data are the same as those in the previous example. The optimal value is 5064 . Given that 
Citation: Wang HF, Lin HS (2014) Optimal Process/Reprocess Production Mix for Multiple Orders in Multiple Periods. Ind Eng Manage 3: 144. doi: 10.4172/2169-0316.1000144

Page 7 of 8

\begin{tabular}{|c|c|c|c|c|}
\hline $\begin{array}{r}\text { Supply } \\
\text { Order }\end{array}$ & $1^{\text {st }}$ & $2^{\text {nd }}$ & $3^{\text {rd }}$ & $4^{\text {th }}$ \\
\hline $1^{\text {st }}$ & $(0,0,95,88)$ & $\mathbf{0}$ & $\mathbf{0}$ & $\mathbf{0}$ \\
\hline $2^{\text {nd }}$ & & $(0,110,90,0)$ & $\mathbf{0}$ & $\mathbf{0}$ \\
\hline $3^{\text {rd }}$ & & & $(0,160,0,0)$ & $(102,0,0,0)$ \\
\hline $4^{\text {th }}$ & & & & $(100,180,0,0)$ \\
\hline
\end{tabular}

Table 11: Optimal Periodic Allocation for Retailers (R1, R2, R3, R4) from Periods $1,2,3,4$ with Maximal Delay $(12,12,12,12)$ by the PMM.

\begin{tabular}{|c|c|c|c|c|}
\hline $\begin{array}{c}\text { Supply } \\
\text { Order }\end{array}$ & $5^{\text {th }}$ & $6^{\text {th }}$ & $7^{\text {th }}$ & $8^{\text {th }}$ \\
\hline $1^{\text {st }}$ & $\mathbf{0}$ & $\mathbf{0}$ & $\mathbf{0}$ & $\mathbf{0}$ \\
\hline $2^{\text {nd }}$ & $\mathbf{0}$ & $\mathbf{0}$ & $\mathbf{0}$ & $\mathbf{0}$ \\
\hline $3^{\text {rd }}$ & $\mathbf{0}$ & $\mathbf{0}$ & $\mathbf{0}$ & $\mathbf{0}$ \\
\hline $4^{\text {th }}$ & $(60,0,0,0)$ & $\mathbf{0}$ & $\mathbf{0}$ & $\mathbf{0}$ \\
\hline $5^{\text {th }}$ & $(110,60,30,0)$ & $\mathbf{0}$ & $\mathbf{0}$ & $\mathbf{0}$ \\
\hline $6^{\text {th }}$ & & $(0,0,20,228)$ & $(60,70,0,72)$ & $\mathbf{0}$ \\
\hline $7^{\text {th }}$ & & & $(2,1,2,4)$ & $\mathbf{0}$ \\
\hline $8^{\text {th }}$ & & & & $(34,95,78,88)$ \\
\hline
\end{tabular}

Table 12: Optimal Periodic Allocation for Retailers (R1, R2, R3, R4) from Periods $5,6,7,8$ with Maximal Delay $(12,12,12,12)$ by PMM

\begin{tabular}{|c|c|c|c|c|c|}
\hline $\begin{array}{c}\text { Supply } \\
\text { Order }\end{array}$ & $9^{\text {th }}$ & $10^{\text {th }}$ & $11^{\text {th }}$ & $12^{\text {th }}$ & $13^{\text {th }}$ \\
\hline $1^{\text {st }}$ & $\mathbf{0}$ & $\mathbf{0}$ & $\mathbf{0}$ & $\mathbf{0}$ & $\mathbf{0}$ \\
\hline $2^{\text {nd }}$ & $\mathbf{0}$ & $\mathbf{0}$ & $\mathbf{0}$ & $\mathbf{0}$ & $\mathbf{0}$ \\
\hline $3^{\text {rd }}$ & $\mathbf{0}$ & $\mathbf{0}$ & $\mathbf{0}$ & $\mathbf{0}$ & $\mathbf{0}$ \\
\hline $4^{\text {th }}$ & $\mathbf{0}$ & $\mathbf{0}$ & $\mathbf{0}$ & $\mathbf{0}$ & $\mathbf{0}$ \\
\hline $5^{\text {th }}$ & $\mathbf{0}$ & $\mathbf{0}$ & $\mathbf{0}$ & $\mathbf{0}$ & $\mathbf{0}$ \\
\hline $6^{\text {th }}$ & $\mathbf{0}$ & $\mathbf{0}$ & $\mathbf{0}$ & $\mathbf{0}$ & $\mathbf{0}$ \\
\hline $7^{\text {th }}$ & $\mathbf{0}$ & $\mathbf{0}$ & $\mathbf{0}$ & $\mathbf{0}$ & $\mathbf{0}$ \\
\hline $8^{\text {th }}$ & $(51,0,0,0)$ & $\mathbf{0}$ & $\mathbf{0}$ & $\mathbf{0}$ & $\mathbf{0}$ \\
\hline $9^{\text {th }}$ & $(96,110,0,0)$ & $\mathbf{0}$ & $\mathbf{0}$ & $\mathbf{0}$ & $\mathbf{0}$ \\
\hline $10^{\text {th }}$ & & $(118,0,0,152)$ & $(32,0,0,0)$ & $\mathbf{0}$ & $\mathbf{0}$ \\
\hline $11^{\text {th }}$ & & & $(160,0,0,0)$ & $\mathbf{0}$ & $\mathbf{0}$ \\
\hline $12^{\text {th }}$ & & & & $(0,56,30,250)$ & $(110,4,0,0)$ \\
\hline $13^{\text {th }}$ & & & & & $(60,70,20,0)$ \\
\hline
\end{tabular}

Table 13: Optimal Periodic Allocation for Retailers (R1, R2, R3, R4) from Periods $9,10,11,12$ with Maximal Delay $(12,12,12,12)$ by PMM.

\begin{tabular}{|c|c|c|c|c|c|c|c|c|c|}
\hline Retailer & $1^{\text {st }}$ & $2^{\text {nd }}$ & $3^{\text {rd }}$ & $4^{\text {th }}$ & $5^{\text {th }}$ & $6^{\text {th }}$ & $7^{\text {th }}$ & $8^{\text {th }}$ & $9^{\text {th }}$ \\
\hline R1 & 0 & 0 & 0 & 100 & 170 & 0 & 62 & 34 & 147 \\
\hline R2 & 95 & 110 & 160 & 180 & 60 & 0 & 71 & 95 & 110 \\
\hline R3 & 0 & 90 & 0 & 0 & 30 & 20 & 2 & 78 & 0 \\
\hline R4 & 88 & 0 & 0 & 0 & 0 & 228 & 76 & 88 & 0 \\
\hline$t$ & $10^{\text {st }}$ & $11^{\text {nd }}$ & $12^{\text {rd }}$ & $13^{\text {th }}$ & & & & & \\
\hline Retailer & & & & & & & & & \\
\hline R1 & 118 & 192 & 0 & 170 & & & & & \\
\hline R2 & 0 & 0 & 56 & 74 & & & & & \\
\hline R3 & 0 & 0 & 30 & 20 & & & & & \\
\hline R4 & 152 & 0 & 250 & 0 & & & & & \\
\hline
\end{tabular}

Table 14: Revised Optimal Allocation Strategy by Reduced PMM.

our goal is to identify the difference between the PMM and the reduced PMM, we only provide the optimal allocation tableau for each model. Tables 11-13 show the allocation tableau for the PMM, whereas Table 14 shows the allocation tableau for the reduced PMM. A feature of the reduced PMM is that, although both tableaus could provide product delivery information to the producer, the reduced PMM simplifies the allocation tableau. This tableau is more readable for decision makers because the producer only needs to know the number of products supplied to retailer $j$ in each period.

To connect these two kinds of tableaus, we simply add total supply to retailer $\mathrm{j}$ in period $\mathrm{t}$ in the PMM, thus enabling us to determine the total supply to retailer $j$ in period $t$ in the reduced PMM. For example, from Table 12, we observed that the supply to retailer 4 's $6^{\text {th }}$ period order is 72 , and the supply to retailer 4's $7^{\text {th }}$ period order is 4 . Therefore, the total supply to retailer 4 in period 7 is 76 , which is located at $(4$, 7) in Table 14. By contrast, Theorem 1 implies that alternative optimal allocation strategies might exist. As such, we can infer tableaus for the reduced PMM from the multiple tableaus for the PMM.

\section{Summary and Conclusion}

In this study, we developed an analytical model, called the PMM, to deal with production planning that involves reprocessing and inseparable orders in multiple periods. The property of the PMM and the special case leading to the reduced PMM model are both investigated, especially the existing condition of multiple optimal solutions. Numerical examples are also provided to show how the PMM and the reduced PMM work.

Furthermore, considering managerial implications, we not only provide the existing condition of multiple optimal solutions for the alternative allocation strategy, but also analyze two extreme values of the minimum ratio of accepted orders $\left(M R S O_{j}\right)$, which are $M R S O_{j}^{*}$ and $M R S O_{j}^{* *}$, for decision support. Based on their preferences, decision makers may refer to $M R S O_{j}^{*}$ and $M R S O_{j}^{*}$ to tradeoff between the returned profit and the service level with regards the corresponding number of accepted orders.

In conclusion, apart from the information derived from the traditional production planning model, this study provides additional information for decision support. Such information can help managers decide on which orders the producer should accept and how the final products should be allocated to the retailers within each period to achieve the maximum net profit.

For future research, the scope of the PMM can be extended to a multiproduct production plan. The producer usually sells more than one item in the market; thus, the production of multiple products should be considered.

\section{Acknowledgement}

The authors acknowledge the financial support from the Ministry of Science and Technology, Taiwan, ROC with project number: NSC 100-2221-E007-062-MY3.

\section{References}

1. ljomah WL, Childe S, McMahon C (2004) Remanufacturing: A key Strategy for Sustainable Development. Proceedings of the 3rd International Conference on Design and Manufacture for Sustainable Development, Cambridge University Press.

2. Lund RT, Hauser WM (2010) Remanufacturing-An American Perspective. ICRM2010-Green Manufacturing, Ningbo, China.

3. Golany B, Yang J and Yu G (2001) Economic Lot-sizing with Remanufacturing Options. IIE Transactions 33: 995-1003.

4. Pan Z, Tang J, Liu O (2009) Capacitated Dynamic Lot Sizing Problems in Closed Loop Supply Chain. European Journal of Operational Research 198 810-821.

5. Richter K, Sombrutzki M (2000) Remanufacturing planning for the reverse Wagner/Whitin models. European Journal of Operational Research 121: 304-315. 
Citation: Wang HF, Lin HS (2014) Optimal Process/Reprocess Production Mix for Multiple Orders in Multiple Periods. Ind Eng Manage 3: 144. doi: 10.4172/2169-0316.1000144

Page 8 of 8

6. Wang HF, Fu CY (2014) Batch Production Plan for Periodic Demands with Uncertain Recycling Rate in a Closed-Loop Supply System. Supply Chain Management Under Fuzziness, Studies in Fuzziness and Soft Computing 313
7. Sutherland JW, Adler DP, Haapala KR, Kumar V (2008) A Comparison of Manufacturing and Remanufacturing Energy Intensities with Application to Diesel Engine Production. CIRP Annals -Manufacturing Technology 57: 5-8. 